\title{
EVOLUÇÃO TECTÔNICA DOS TERRENOS ENTRE OS CINTURÕES RIBEIRA E DOM FELICIANO (PR-SC)
}

\author{
MIGUEL A.S. BASEI*, OSWALDO SIGA, Jr.*, ADILSON MACHIAVELLI* e FERNANDO MANCINI*
}

\begin{abstract}
TECTONIC EVOLUTION OF TERRAINS BETWEEN THE DOM FELICIANO AND RIBEIRA BELTS (SOUTHERN-BRAZIL). This paper discusses the tectonic interpretation of the late Pre-Cambrian to lower Paleozoic Terrains of the states of Paraná and Santa Catarina in southern Brazil. The abandoning of the term "Median Joinville Massif' is proposed. It is substituted by three tectonic units recognised hi this region: Curitiba Microplate (north), Luís Alves Microplate (south) and Costeiro Granitoid Belt (east). Lithological, geochcmical and gcochronological data obtained in these terrains confirm their differences and allow the separation of the three units proposed whose agglutination took place during the Brasiliano and Rio Doce Orogenies between 650 and 550 Ma ago produced by subductions and collisions related to the assemblage of Gondwana.
\end{abstract}

Keywords: Microplate, subduction, collision, granitogenesis, crustal thickness, orogeny.

\begin{abstract}
RESUMO Este trabalho apresenta uma interpretação da evolução geotectônica de terrenos pré-cambrianos a eopaleozóicos situados entre os Cinturões Ribeira (norte) e Dom Feliciano (sul), nos Estados do Paraná e Santa Catarina. E proposto o abandono do termo Maciço Mediano de Joinville e sua substituição por três unidades que representam esses terrenos: Microplaca Curitiba (norte), Microplaca Luís Alves (sul) e Cinturão Granitóide Costeiro (leste). Diferenças litológicas, estruturais, geoquímicas e geocronológicas entre as rochas que constituem essas unidades consubstanciam a individuatização dessas três entidades, cuja aglutinação deu-se somente ao final do Proterozóico Superior e início do Paleozóico Inferior durante as orogeneses Brasiliana (clímax a $650 \pm 50$ Ma) e Rio Doce (clímax a $550 \pm 50 \mathrm{Ma}$ ), corno produto de sucessivas subducções e colisões relacionadas à constituição do supercontinente Gondwana.
\end{abstract}

Palavras-chaves: Microplaca, subducção, colisão, granitogênese, espessamento litosférico, orogênese.
INTRODUÇÃO Os estudos geológicos, envolvendo características litológicas, petrográficas, estruturais, geocronológicas e geoquímicas, além de dados gravimétricos, propiciaram avanços significativos na compreensão da evolução geotectônica do setor sudeste paranaense e nordeste catarinense.

As inúmeras propostas existentes para os modelos geológicos da região podem ser exemplificados pelas diversas denominações geotectônicas envolvendo total ou parcialmente esta porção do escudo brasileiro: Maciço Barra Velha - Morretes (Carneiro 1974), Alto Tectônico Pien - Morretes (Cordani 1974); Maciço Mediano de Joinville (Hasui et al. 1975); Complexo Granulítico de Santa Catarina (Hartmann et al. 1979); Cráton de Luís Alves (Kaul 1980, 1984); Cinturão Móvel de Joinville (Silva 1984); Maciço Marginal de Curitiba e Cráton Rio de La Plata (Basei 1985 e Basei et al 1988); Cráton de Guaruva - São Francisco do Sul e Cinturão Móvel Granulítico (Silva 1987).

Neste trabalho, mantidos os contornos propostos para o Maciço de Joinville por Hasui et al. (1975), a evolução tectônica dos terrenos granito-gnáissicos é enfocada pela interação entre três entidades tectônicas distintas, através de sucessivas subducções seguidas de colisões continentais, cujos eventos terminais teriam atingido o Paleozóico Inferior.

As unidades geotectônicas caracterizadas são representadas pelas Microplacas Curitiba, Luís Alves e, na porção litorânea, pelo Cinturão Granitóide Costeiro, separados entre si por importantes zonas de cisalhamento (Fig. 1).

QUADRO GEOLÓGICO Os dois perfis apresentados nas figuras 2 e 3 representam secções geológicas onde podem ser observados os principais litotipos dos três diferentes domínios tectônicos. Eles representam em maior detalhe a porção crustal superior dos perils $\mathrm{AB}$ e $\mathrm{CD}$ apresentados na figura 1. $\mathrm{Na}$ secção Curitiba-Pien (Fig. 2), são enfatizadas as relações dos gnaisses do domínio Norte (Microplaca Curitiba) com as rochas granulíticas do domínio sul (Microplaca Luís Alves). Esse contado ocorre na região de Pien, sendo caracterizado por importante zona de cisalhamento (empurrão) que coloca, em termos relativos, as rochas do domínio norte por sobre os granulitos da porção sul.

Nesse mesmo perfil, de norte para sul, entre Curitiba e Mandirituba, são observados dois pacotes de gnaisses bandados, migmatíticos, sendo um deles caracteristicamente a mesossoma de biotita anfibólio gnaisses e leucossoma claro de composição tonalito-granodiorítica. O segundo é composto por gnaisses graníticos bandados com presença restrita de biotita gnaisses lepidoblásticos. Nos dois conjuntos são freqüentes intercalações de corpos máficos (anfibolitos e biotita-granada anfibolitos) com dimensões e formas variadas. Diversas idades indicam valores concordantes ao redor de 2,1 Ga (Siga 1992) para esses gnaisses, sugerindo terem os mesmos sido gerados no Proterozóico Inferior.

São comuns, nos dois tipos de gnaisses, a presença, em diferentes graus, de feições relacionadas a migmatização de idade brasiliana (Siga 1992), cujos mobilizados róseos finos a médios, até pegmatóides, foliados ou não, são os indicadores mais evidentes (Fig. 4a).

Esses gnaisses bandados, através de uma zona de cisalhamento, na borda meridional dos terrenos desta microplaca, passam para granitóides cálcio-alcalinos de granulação grossa a média, em geral de cor rosada e composição predominante monzogranítica. São rochas atribuídas a raízes de provável arco magmático do Proterozóico Superior (Machiavelli 1991 e Machiavelli et al. 1991). O limite tectônico com o domínio a sul é evidenciado pelas rochas ultramáficas serpentinizadas (região de Pien) e pela presença de milonitos. É possível observar, nesse local, importante anomalia magnética negativa (Mantovani et al. 1989) e uma mudança do padrão geo-cronológico K-Ar que, a norte apresenta valores no Proterozóico Superior, e a sul valores no Proterozóico Inferior (Siga et al 1990). 


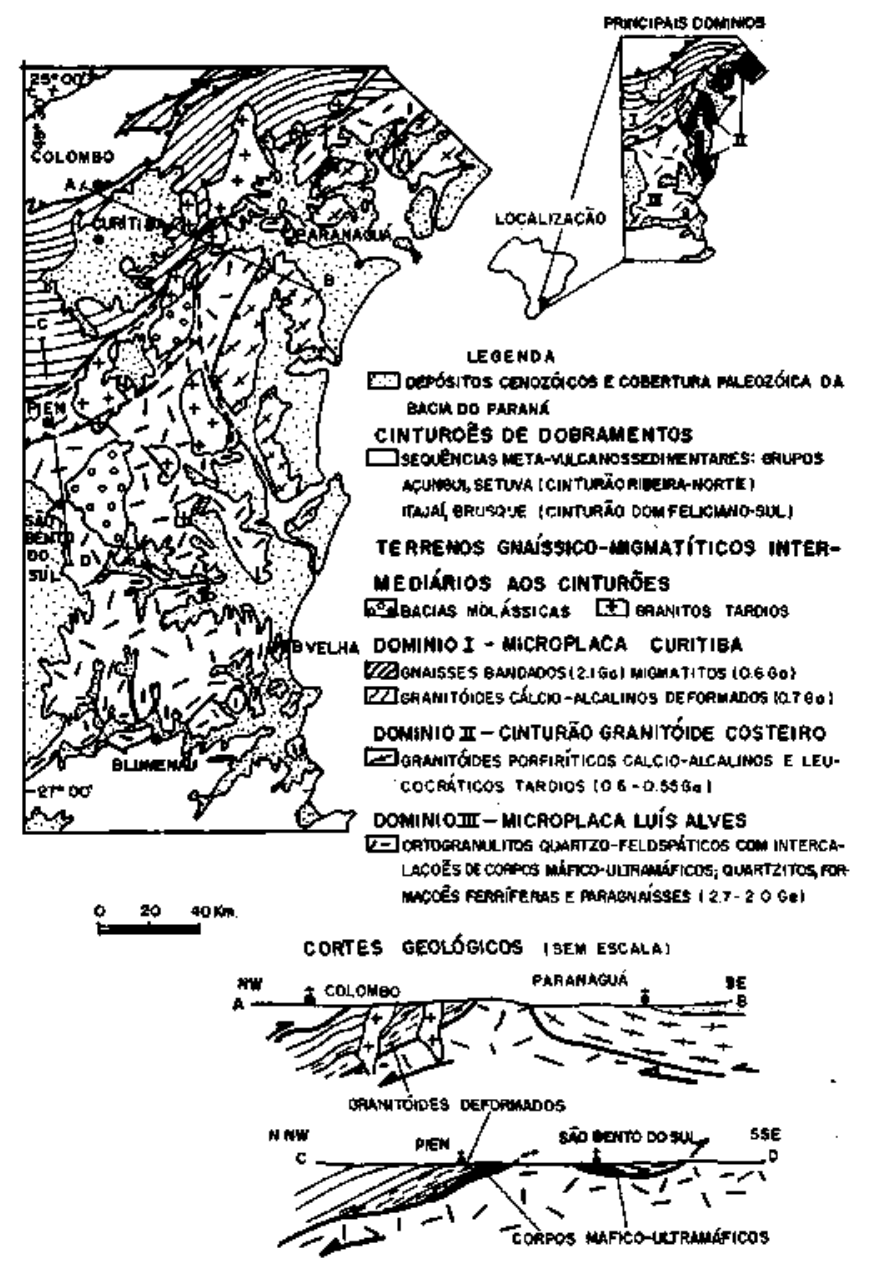

Figura 1 - Compartimentação tectônica da porção sudeste do Paraná e nordeste de Santa Catarina

Figure 1 -Tectonic outline of Precambrian to lower Paleozoic terrains of South Brazil (Paraná and Santa Catarina States)

Gnaisses granulíticos, bandados a maciços, de composição tonalito-granodiorítica e com freqüentes encraves de granulitos máfícos, representam os litotipos característicos da Microplaca Luís Alves. Idades obtidas por diversas metodologias evidenciam evolução policíclica complexa com início no Arqueano (-3.2 Ga) e com último retrabalhamento no Proterozóico Inferior (Basei 1985, Basei \& Teixeira 1987, Mantovani et al. 1987).

As descrições efetuadas ao longo do perfil Curitiba-Pien são igualmente válidas para a metade oeste da secção CuritibaParanaguá (Fig. 3), onde são observadas, na mesma seqüência, as unidades de gnaisses bandados migmatíticos, de granitóides deformados e de gnaisses granulíticos, descritos anteriormente.

A porção leste desse segundo perfil é caracterizada por diferentes gerações de granitóides do domínio costeiro (Lopes 1984). Predominam granitos cálcio-alcalinos, de granulação grossa com megacristais de microclínio, ricos em biotita, com anfibólio e epídoto como fases minerais importantes. Biotita granitóides cinza-médio e granitos leucocráticos com duas micas são também observados. Essas rochas constituem o Cinturão Granitóide Costeiro, cujo representante principal foi caracteri-zado na região como Batólito Paranaguá, com valores radiomé-tricos distribuídos entre 620 e $450 \mathrm{Ma}$ (Basei et al 1990a).

CARACTERÍSTICAS ESTRUTURAIS Comportamento estrutural coerente é verificado entre unidades geotectônicas, semelhantes mesmo quando reconhecidas em perfis geológicos diferentes. Para todo o domínio norte dos terrenos agregados, é observada orientação predominantemente nordeste, que inclui a superfície Sn (principal) dos gnaisses bandados, dos granitóides deformados e dos ultramafitos de Pien. Essas superfícies correspondem à foliação $\mathrm{S} 2$, paralela ao bandamento nos gnaisses (Figs. 4b, c e d), e à foliação $\mathrm{S} 1$ (com características de cisalhamento dúctil) nos granitos deformados e nos ultramafitos da Campina dos Crispins (Pien). É marcante, nos estereogramas apresentados, a semelhança no comportamento espacial dessas superfícies nos granitóides deformados e nos ultramafitos, geradas sob condições de metamorfismo facies xisto verde, respectivamente com máximos a N45F7 $68 \mathrm{NW}$ e N51E/59NW. As informações geocronológicas disponíveis sugerem idades do Proterozóico Superior para o desenvolvimento da superfície Sn.

$\mathrm{Na}$ maioria das unidades do domínio oeste, principalmente nos estereogramas dos gnaisses bandados (Figs. 2 e 3), é verificado o dobramento cilíndrico da foliação $\mathrm{Sn}$, admitindo direção axial NE-SW. Este dobramento, que admite clivagem planoaxial, é facilmente observado no afloramento e corresponde à principal fase de dobramento regional a afetar a foliação Sn. Nos gnaisses bandados é um dobramento $\mathrm{D}_{3}$, enquanto nos granitóides e rochas ultramáficas de Pien é uma fase $\mathrm{D}_{2}$. Os estereogramas da figura 2 indicam para os eixos construídos valores de N43E/14, N50E/16 e S76W/38 e no perfil 3 eixo com atitude N58E/5.

A orientação do bandamento no domínio dos gnaisses granulíticos é francamente noroeste, nos dois perfis, diferente do padrão nordeste dos demais conjuntos. Esse bandamento, que é uma superfície S2 (Figs. 4e e f) gerada em condições de alto grau, apresenta-se redobrado, com atitude do planoaxial NW-SE e eixos com orientação S33E/50 e S50E/56, respectivamente nos dois perfis discutidos (Figs. 2 e 3 ).

No domínio costeiro, a principal foliação observada nos granitóides é também superfície S1, heterogênea, ocorrendo porções do corpo que se mostram praticamente isótropas, regiões onde o mesmo está bastante deformado e áreas onde é difícil a distinção entre feições associadas com fluxo magmático e superfícies geradas tectonicamente. É sugerido que a época de colocação desses corpos seja próxima da idade da deformação obtida no método Rb-Sr (ca. $550 \mathrm{Ma}$, Basei et al. 1990a).

A orientação principal nesse domínio é nordeste, devendo ser destacada as observações efetuadas na pedreira Matinhos, próxima à localidade homônima, a sul de Paranaguá, onde os megacristais estão bastante deformados, com aspecto de au-gens, e contidos na superfície Sn principal que possui orien-tação N2E/35SE. Essas lineações do tipo A, evidenciadas pelo estereograma mais a leste da figura 3, possuem orientação SE e estão em acordo com a interpretação de que processos relacionados a nappes de empurrão sejam os responsáveis pela justaposição do domínio costeiro à Microplaca Luís Alves.

PRINCIPAIS ÉPOCAS DE SUBDUCCÕES E COUSOES A atual configuração dos terrenos entre os Cinturões Ribeira e Dom Feliciano, caracterizada pela aglutinação de três entidades geotectônicas distintas, foi elaborada por processos de sucessivas subducções seguidas de colisões com sentido predominante de acresção de leste para oeste.

Durante o final do Proterozóico Superior com continuidade até o Cambriano, o atual quadro tectônico foi estabelecido como resultado de processo de colagens relacionadas com a formação do Gondwana Ocidental. Na passagem ProterozóicoPaleozóico Inferior, teria produzido, como resultado do choque dos Crátons Congo-Kalahari contra o conjunto dos Crátons São Francisco-Paraná e Amazônico, o amalgamento de todas as microplacas existentes entre essas grandes massas continentais. As massas continentais representariam restos de 


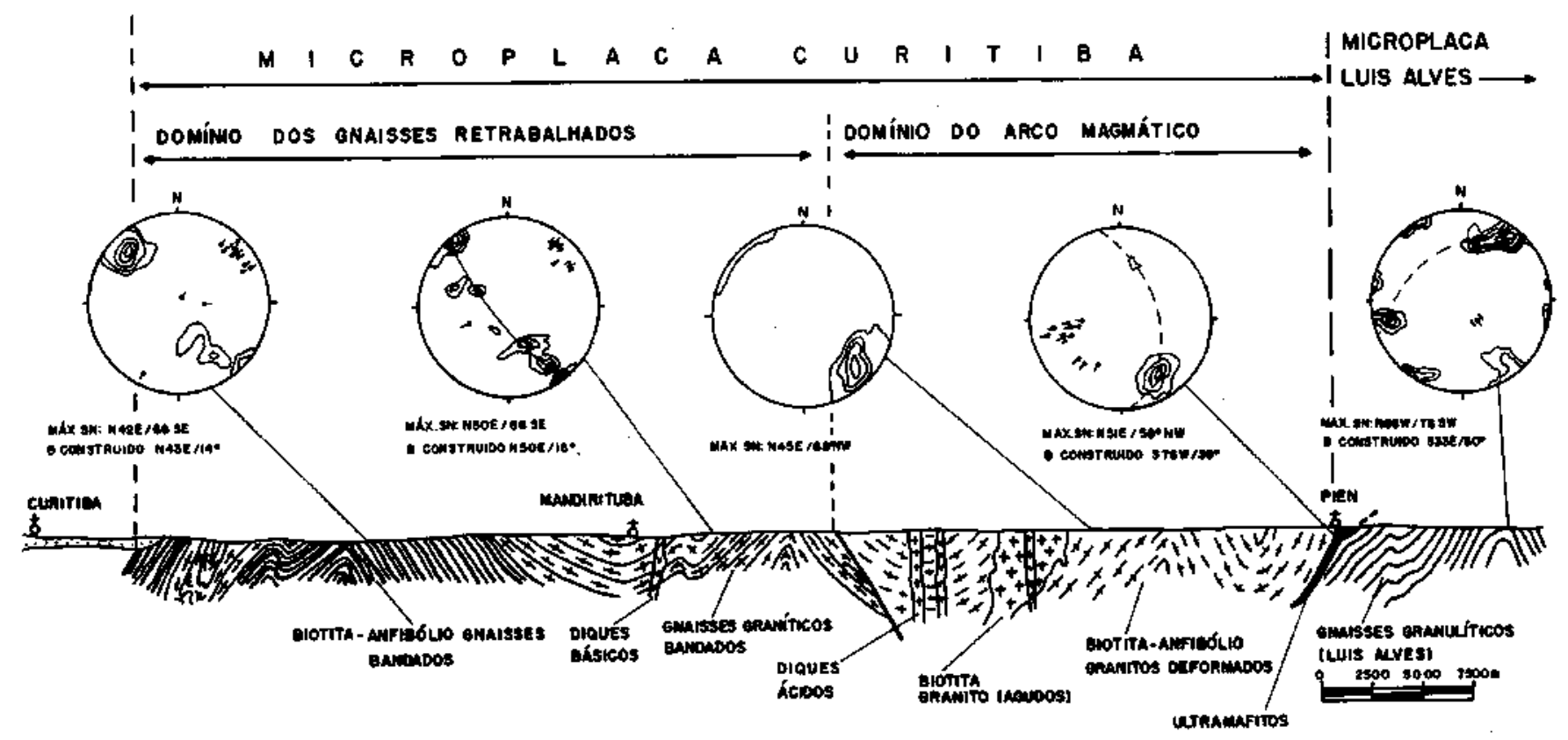

Figura 2-Perfil Curitiba-Pien

Figure 2 - Geological section between Curitiba $(\mathrm{N})$ and Pien (S), Paraná State

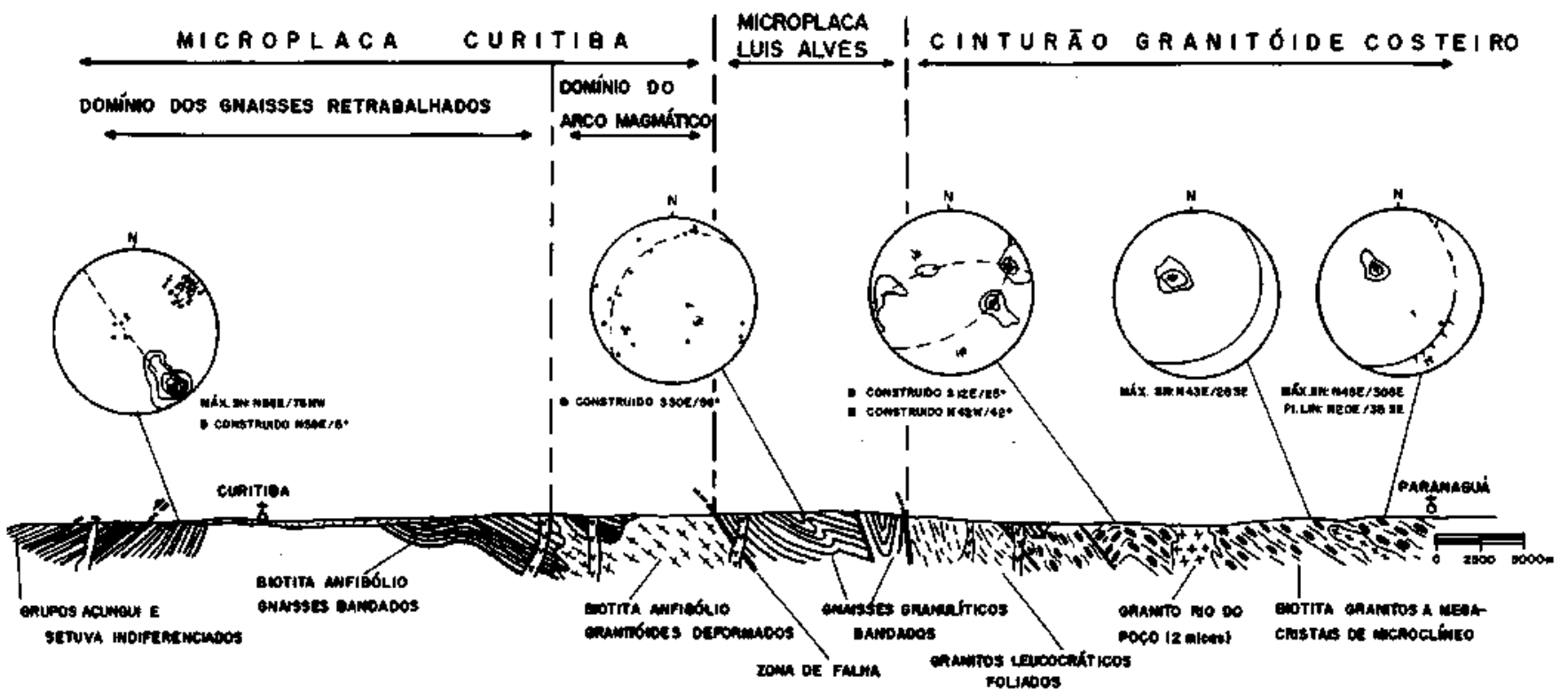

Figura 3 - Perfil Curitiba-Paranagiiá

Figure 3 - Geological section between Curitiba (W) and Paranaguá (E), Paraná State

"embasamento" em meio aos cinturões de dobramentos gerados ou retrabalhados nessa época (Basei et al. 1988, Brito Neves\&Cordani 1991).

Pelo apresentado, a movimentação é entendida das Microplacas Curitiba e Luís Alves rumo noroeste por debaixo do Cinturão Ribeira (subducção A). Na figura 5, é apresentado um quadro sinóptico no qual são sugeridas, baseado nos dados radiométricos e geoquímicos disponíveis, as principais épocas de subducções e colisões, bem como o posicionamento das suturas decorrentes.

É entendido que o processo de subducção da microplaca Curitiba sob o Cinturão Ribeira teria sido iniciado ao redor de $800 \pm 50 \mathrm{Ma}$, como decorrência da abertura de um oceano a sul da posição atual de Pien (PR) que sepa- raria esse domínio setentrional da microplaca meridional Luís Alves.

Ao redor de $700 \pm 50 \mathrm{Ma}$ (idade sugerida pelos granitóides do arco na região de Pien), é iniciado o processo de fechamento desse oceano e a conseqüente geração do arco magmático produzido pela subducção por sob a placa Curitiba dessa crosta oceânica (Fig. 5a). É sugerido que, enquanto esse processo estaria ocorrendo na região de Pien, a relação da Microplaca Curitiba com o Cinturão Ribeira já seria colisional, produzindo, pelo underthrusting dessa microplaca, por sob o Cinturão Ribeira com transporte relativo de NW para SE das coberturas metavulcanossedimentares. O arco magmático de Três Córregos seria gerado nessa época em posição de um arco magmático continental (Fig. 5a), na borda do Cráton do Paraná. 

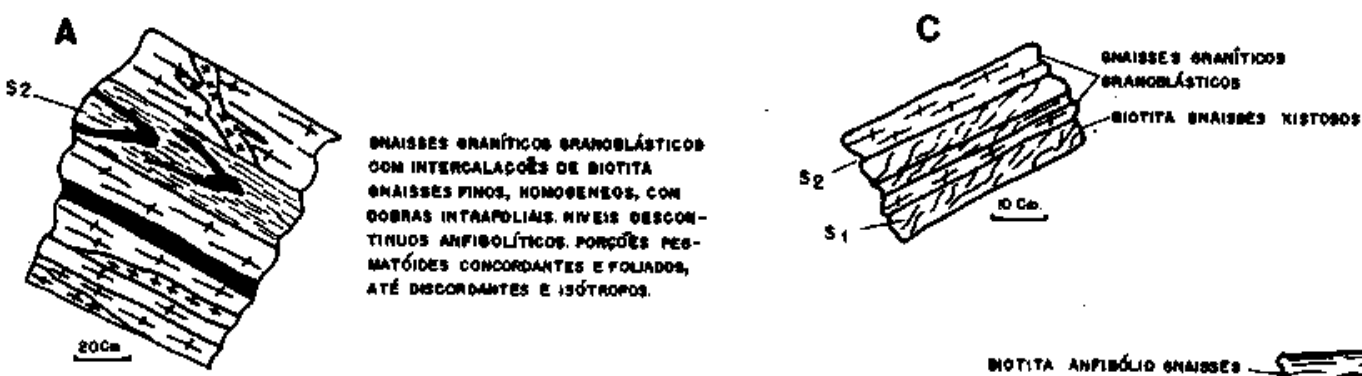

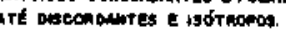
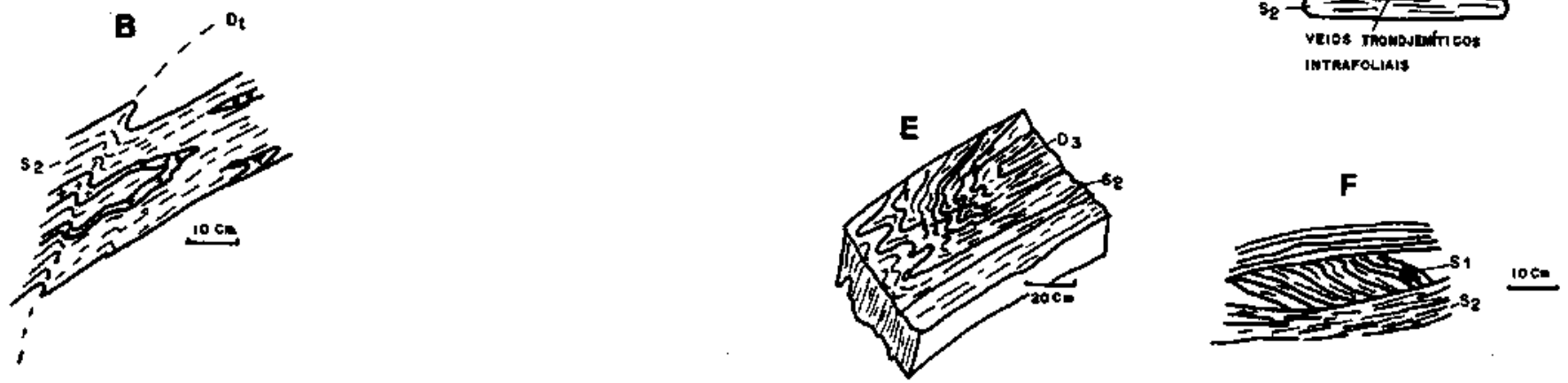

Figura 4 - Esquemas macroscópicos de estruturas observadas em afloramentos. A. Gnaisses graníticos bandados (sul de Mandirituba/PR); B. gnaisses tonalíticos a quartzo-dioriticos cinza-escuro com porfiroblastos de anfibólios e dobras intrafoliais (BR. 376 a sudeste de Curitiba/PR); $\boldsymbol{C}$. gnaisses graniticos bandados (Mandirituba/PR); D. anfibólio gnaisses tonalíticos (da Pedreira Atuba, Curitiba/PR); E. gnaisses granuliticos bandados dobrados em dobras D3 isoclinais (Pomerode/SC); $\boldsymbol{F}$. detalhe da amostra $4 E$ com evidências da transposição dafoliação $S_{I}$

Figure 4 - Outcrop schemes of mesoscopic structures from Curitiba and Luís Alves Microplates

Esse modelo explicaria a dupla vergência tectônica do Cinturão Ribeira, que é para NW na região a norte do Batólito Três Córregos e para SE na região a sul do mesmo.

A zona de falha da Lancinha deve representar, em superfície, a materialização da sutura entre a Microplaca Curitiba e os terrenos a norte. A importância desse lineamento dentro de um contexto colisional regional já tinha sido enfatizada por diversos autores (Kaul 1984, Campanha et al. 1987, Soares 1988 e Fiori 1991).

As seqüências a sul desse lineamento (Capiru, Turvo-Cajati, Setuva etc.) devem ter seu referencial paleogeográfico na Microplaca Curitiba e não nas áreas cratônicas a norte (Cráton do Paraná) como as demais coberturas da Faixa Apiaí (Votuverava, Águas Claras, Iporanga, Itaiacoca etc.), tendo sido colocadas lado a lado somente após a colisão.

Essa suposição baseia-se, entre outras informações, em indicações paleogeográficas que sugerem que a Formação Capiru teria uma plataforma a sudeste e conteúdo estromatolítico diferente dos demais calcários da Faixa Apiaí (Fairchild 1977).

$\mathrm{O}$ fechamento completo do oceano existente entre as microplacas Curitiba e Luís Alves e a conseqüente colisão teria ocorrido ao redor de $610 \mathrm{Ma}$, conforme sugerido pelas idades relacionadas ao desenvolvimento da foliação e do metamorfismo fácies xisto verde dos granitóides do arco magmático (Fig. $5 b$ ), processos esses gerados quando do processo colisional.

A justaposição do domínio costeiro deu-se tardiamente à colagem das microplacas Curitiba e Luís Alves. Os valores de idades e a assinatura isotópica desse terreno o diferencia claramente dos demais (Basei et al. 1990b), e sugerem sua evolução a partir do retrabalhamento de rochas crustais no intervalo 600-550 Ma (Fig. 5c). Esse segmento pouco expressivo na região teria sido gerado na orogênese Rio Doce (Campos 1991), que baliza grande parte da porção oriental brasileira. Esses granitóides devem representar a continuidade dos terrenos do Complexo Costeiro, que se estendem desde o sul da
Bahia (Siga 1986, Basei et al. 1990a, b) e continuam a sul nos Estados de Santa Catarina e Rio Grande do Sul representados principalmente pelo domínio granitóide do Cinturão Dom Feliciano.

Com a justaposição desses três blocos crustais, ocorreu expressivo vulcanismo ácido e intermediário, exemplificado pelas Bacias de Campo Alegre e Guaratubinha, e a importante granitogênese Suíte Serra do Mar (Kaul 1984). Tais manifestações foram produzidas pelos ajustes crustais decorrentes da procura por condições de maior estabilidade, após o espessamento litosférico provocado na região pelas colisões precedentes. Esta granitogênese, caracteristicamente alcalina e com anfibólio sódico (riebeckita), tem idade entre 550 e $500 \mathrm{Ma}$. (Siga 1992), similar ao intervalo observado para o vulcanismo.

CONCLUSÕES No quadro da tabela 1 estão representadas algumas das principais conclusões sugeridas neste trabalho. São elas:

1. Os terrenos gnáissico migmatíticos dos Estados do Paraná e Santa Catarina não representam entidade antiga, una e de comportamento estável, localizada entre os Cinturões Ribeira (norte) e Dom Feliciano (sul). Sua constituição seria tanto sincrônica, como, também, posterior às principais épocas de deformações e metamorfismos observadas nesses cinturões; 2. A justaposição das entidades geotectônicas que o constituem (Microplacas Curitiba e Luís Alves e Cinturão Granitóide Costeiro) teria se dado por processos de subducções e colisões que ocorreram durante o Proterozóico Superior e o Cambriano, como parte de processo maior, relacionado à constituição da porção oeste do Gondwana.

3. O magmatismo cálcio-alcalino, de idade proterozóica superior $(700 \pm 50 \mathrm{Ma})$, que ocorre entre Mandirituba a Pien, com uma largura de cerca de $60 \mathrm{~km}$, até o momento representa a melhor exposição de rochas geradas em ambiente de arco magmático conhecidas na região. A sul do mesmo, próximo a Pien, são 

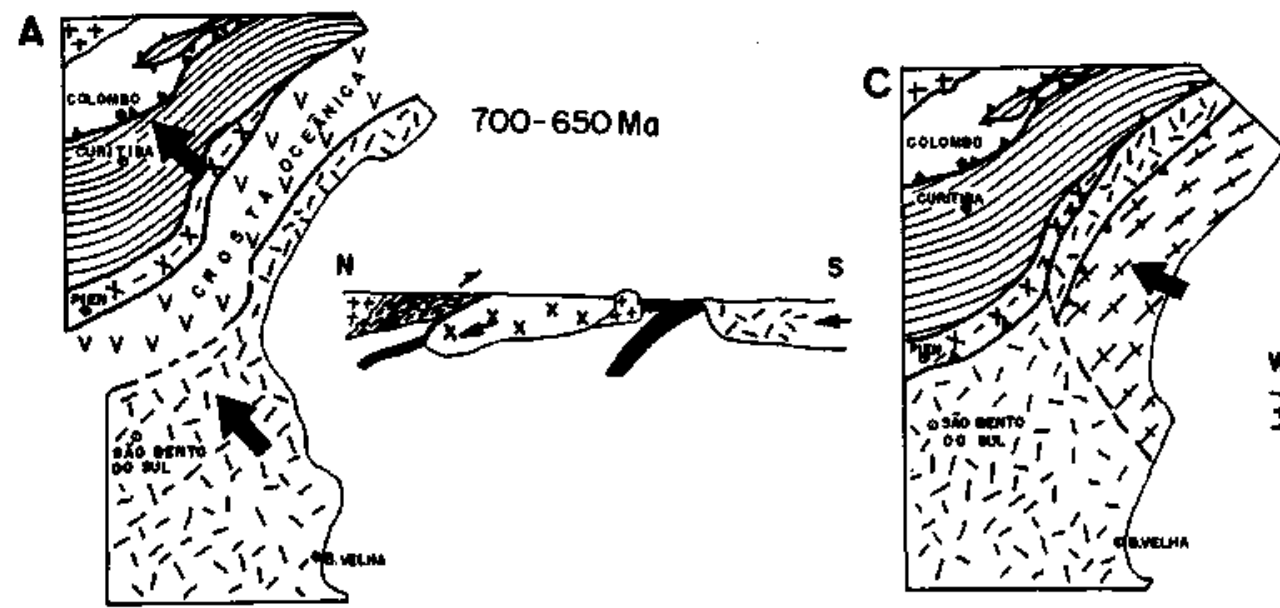

600-550Ma

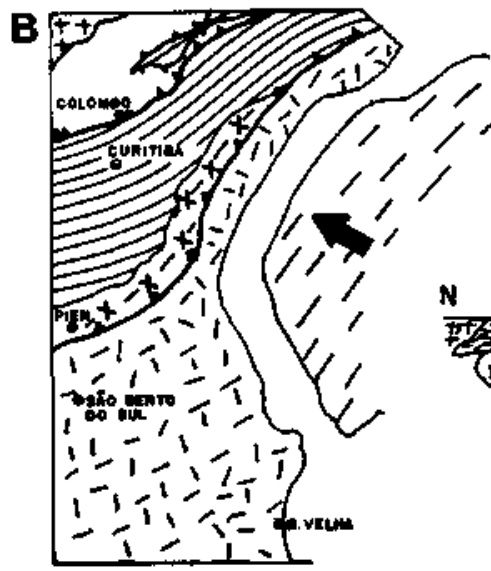

$650-600 \mathrm{Ma}$

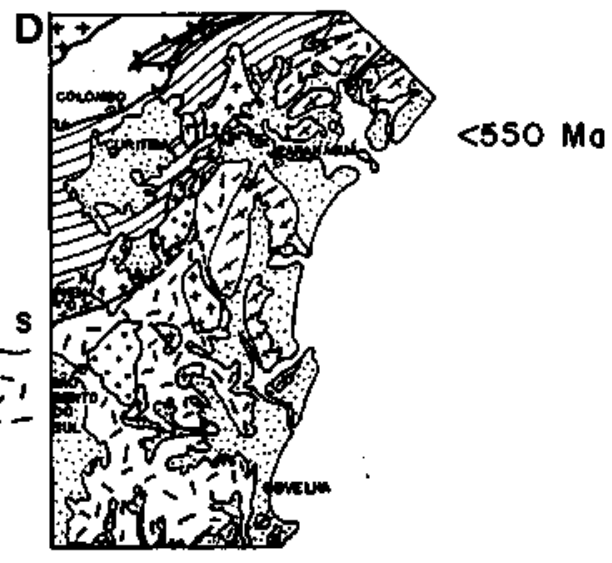

Figura 5 - Principais eventos de subducções e colisões. A. Colisão da microplaca Curitiba com áreas cratônicas à norte, subducção e geração de arco magmático na borda sul da microplaca Curitiba; B. colisão das microplacas Luís Alves e Curitiba, na porção "E" início da Orogênese Rio Doce; $\boldsymbol{C}$. colisão entre o cinturão granitóide costeiro (batólito Paranaguá) e a microplaca Luís Alves, Orogênese Rio Doce; D. atual configuração da porção SE do Paraná e NE de Santa Catarina, no intervalo entre 550 e 500 Ma. Houve a colocação dos granitóides anorogênicos e das bacias molássicas (legenda na Fig. 1)

Figure 5 - Main subductions and collisions of upper Proterozoic age occured in the Curitiba - Barra Velha region, southern - Brazil

Tabela 1- Características tectônicas e geocronológicas dos terrenos intermediários aos Cinturões Ribeira (Norte) e Dom Feliciano (Sul)

Table 1 - Main tectonic and geochronological features of the three tectonic units observed between the Ribeira $(\mathrm{N})$ and Dom Feliciano (S) Belts

\begin{tabular}{|c|c|c|c|c|c|c|}
\hline \multirow{2}{*}{$\begin{array}{c}\text { Principais } \\
\text { Compartimentos }\end{array}$} & \multirow{2}{*}{$\begin{array}{c}\text { Características } \\
\text { Tectônicas }\end{array}$} & \multirow{2}{*}{$\begin{array}{c}\text { Cinemática } \\
\text { Neoproterozóica }\end{array}$} & \multirow{2}{*}{$\begin{array}{c}\text { Magmatismo } \\
\text { Sintectônico } \\
\text { Neoproterozóico }\end{array}$} & \multicolumn{3}{|c|}{ Idades em Rochas Deformadas } \\
\hline & & & & $\begin{array}{c}\text { U-Pb } \\
\text { em zircăo }\end{array}$ & $\begin{array}{c}\mathbf{R b}-\mathbf{S r} \\
\text { Is6cronas }\end{array}$ & $\begin{array}{c}\mathrm{K}-\mathrm{Ar} \\
\text { em minerais } \\
\end{array}$ \\
\hline Domínio Norte I & Microplaca & $\begin{array}{c}\text { Transporte para } \\
\text { NNW }\end{array}$ & $\begin{array}{l}\text { Migmatizaçāo } \\
\text { generalizada. } \\
\text { Granitoides } \\
\text { cálcio-alcalinos } \\
\text { deformados }\end{array}$ & $\begin{array}{c}2.100 \mathrm{Ma} \\
-720 \mathrm{Ma} \\
\text { gran. } \\
\text { deformados } \\
\end{array}$ & $\begin{array}{c}\text { Entre } 700 \mathrm{e} \\
600 \mathrm{Ma} \text {. } \\
\text { Raros valores } \\
\text { acima de } \\
1.500 \mathrm{Ma} \\
\end{array}$ & $\begin{array}{c}\text { Entre } 650 \mathrm{e} \\
500 \mathrm{Ma} \\
\text { Raros valores } \\
\text { acima desse } \\
\text { intervalo } \\
\end{array}$ \\
\hline $\begin{array}{l}\text { Domínio } \\
\text { Costeiro II }\end{array}$ & $\begin{array}{c}\text { Cinturão Granitóide } \\
\text { Costeiro (Batólito } \\
\text { Paranaguá) }\end{array}$ & $\begin{array}{l}\text { Transporte para } \\
\text { WNW }\end{array}$ & $\begin{array}{c}\text { Sujtes } \\
\text { granitoides } \\
\text { calcio-alcalinas } \\
\text { deformadas }\end{array}$ & $614 \mathrm{Ma}$ & $\sim 550 \mathrm{Ma}$ & $\begin{array}{c}\text { Entre } 550 \mathrm{e} \\
450 \mathrm{Ma}\end{array}$ \\
\hline Domínio Sul III & Microplaca & $\begin{array}{l}\text { Transporte para } \\
\text { NNW }\end{array}$ & Inexistente & $\begin{array}{c}\text { Entre } 2.800 \mathrm{e} \\
2.100 \mathrm{Ma}\end{array}$ & $\begin{array}{c}\text { Entre } 2.800 \mathrm{e} \\
2.000 \mathrm{Ma}\end{array}$ & $\begin{array}{c}\text { Entre } 2.200 \mathrm{e} \\
1.700 \mathrm{Ma} \\
\text { para biotita e } \\
\text { anfibólio }\end{array}$ \\
\hline
\end{tabular}


observadas as indicações geológicas e geofísicas da sutura resultante da colisão entre as rnicroplacas Curitiba e Luís Alves. Parte das rochas máfico-ultramáficas observadas em meio aos granitóides cálcio-alcalinos ou aos granulitos do domínio sul parecem representar restos de assoalho oceânico obductados nesse processo.

Somente após a justaposição do Cinturão Granitóide Costeiro, com idades entre 620-500 Ma, que ocorre em seu domínio oriental, a região adquiriu sua configuração atual.

A expressiva granitogênese e o vulcanismo ácido intermediário das bacias molássicas de idade cambriana seriam produtos do rearranjo crustal, decorrentes do espessamento litosférico introduzido pelas colisões que os precederam.

Pelo exposto, é sugerido o abandono do termo Maciço de Joinville e sua substituição pelas denominações das entidades que constituem os terrenos gnáissico-migmatíticos existentes entre os Cinturões Dom Feliciano e Ribeira, quais sejam: Microplaca Curitiba (porção norte), Microplaca Luís Alves (porção sul) e Cinturão Granitóide Costeiro (Fig. 1).

Agradecimentos Os autores agradecem à Fundação de Amparo a Pesquisa do Estado de São Paulo (FAPESP), pelo auxílio fornecido para realização deste trabalho (Processo $\mathrm{n}^{\circ}$ 90/0937-9). Em especial, agradecem aos professores Umberto G. Cordani, Mário C. Campos, Neto e Benjamim B. Brito Neves pelas inúmeras sugestões recebidas após a leitura dos manuscritos. Ao técnico Reynaldo P. Castellón pelo desenho das figuras apresentadas.

\section{REFERÊNCIAS BIBLIOGRÁFICAS}

BASEI, M.A.S. 1985. O Cinturão Dom Feliciano em Santa Catarina. São Paulo. 190 p. (Tese de Doutorado, IG/USP).

BASEI, M.A.S. \& TEIXEIRA, W. 1987. Geocronologia do Pré-Cambriano/ Eopaleozóico de Santa Catarina. In: SILVA, L.A. \& BERTOLUZZI, C.A. eds. Texto Explicativo para o Mapa Geológico do Estado de Santa Catarina -1:500.000. Florianópolis, DNPM/CPRM. 3:91-130.

BASEI, M.A.S.; SIGA, O., Jr.; VASCONCELLOS, J.P.B.C.; SILVA, P.C.S. 1988. Evolução Geotectônica dos Terrenos Pré-Cambrianos a EoPaleozóicos dos Estados do Paraná e Santa Catarina. 120 p. (Rel. FAPESP, projeto 87/0175-9)

BASEI, M.A.S ; SIGA, O. Jr ; REIS NETO, J.M. 1990a O Batolito Paranaguá. Proposição, idade, considerações petrogenéticas e implicações tectônicas. In: CONOR. BRAS. GEOL., 36. Natal, 1990. Anais... Natal, SBG. v. 4, p. 1684-1699.

BRITO NEVES, B.B. \& CORDANI. U.G. 1991. Tectonic evolution of South America during the Late Proterozoic. Free. Research, 53:23-40.

CAMPANHA, G.A.C.; BISTRICHI, C.A.; ALMEIDA, M.A. 1987. Considerações sobre a organização litoestratigráfica da Faixa de Dobramentos Apiaí. In: SIMP. SUL-BRAS. GEOL., 3. Curitiba, 1987. Atas... SBG. v. 2, p. 725-742.

CAMPOS, M.C, NETO. 1991. A Porção Ocidental da Faixa Alto Rio Grande -Ensaio de Evolução Tectônica. São Paulo. 210 p. (Tese de Doutorado, IG/USP).

CARNEIRO, C.D.R. 1974. Esboço e diferenciação tectônica do Pré-Cambriano Superior no sul-sudeste do Brasil. In: CONGR. BRAS. GEOL., 28. Porto Alegre, 1974. Resumo das Comunicações... Porto Alegre, SBG. v. 1, p. 698-700.

CORDANI, U.G. 1974. Comentários sobre da determinações geocronológicas disponíveis nas folhas Assunción e Curitiba. In: Carta Geológica do Brasil ao Milionéssimo. DNPM. p. 58-67.

FAIRCHILD, T.R. 1977. Conophyton and other columnar stromatolites from the upper precambrian Acungui group near Itapeva, SP, Brazil. In: SIMP. GEOL. REG., 1. São Paulo, 1977. Atas... São Paulo, SBG. p. $179-198$

FIORI, A.P. 1991. Tectônica e Estratigrafia do Grupo Açungui a Norte de Curitiba. São Paulo. 261 p. (Tese de Livre Docência, IG/USP).

HARTMANN, L.A.; SELVA, L.C.; ORLANDI, V, Fo. 1979. O Complexo Granulítico de Santa Catarina. Descrição e implicações genéticas. Acta Geol. Leop., 6:93-112.

HASUI, Y.; CARNEIRO, C.D.R.; COIMBRA, A.M. 1975. The Ribeira Fold Belt. Rev. Bras. Geoc., 5(4):257-266.

KAUL, P.F.T. 1980.0 Cráton de Luiz Alves. In: CONGR. BRAS. GEOL., 31. Camboriú, 1980. Anais... Camboriú, SBG. v. 5, p. 2677-2683.

KAUL, P.F.T. 1984. Significado dos granites anorogênicos da Suíte Intrusiva Serra do Mar na evolução da crosta do Sul-Sudeste do Brasil, no âmbito das folhas SG-22 - Curitiba e SG-23 - Iguape. In: CONGR. BRAS. GEOL., 33. Rio de Janeiro, 1984. Anais... Rio de Janeiro, SBG. v. 6, p. 2815-2825.

LOPES, O.F. 1984. O Granito Sin-Tectônico Cubatãozinho: petrogênese e evolução geológica. In: SIMP. SUL-BRAS. GEOL., 1. Curitiba, 1984. Atas... Curitiba, SBG. v. 2, p. 481-490.

MACHIAVELLI, A. 1991. Os Granitóides Deformados da Região de Pien (PR): Um provável Arco Magtnático do Proterozóico Superior. São Paulo. 89 p. (Dissertação de Mestrado, IG/USP)

MACHIAVELLI, A.; BASEI, M.A.S.; SIGA, O., Jr. 1991. Geoquímica e geocronologia dos granitóides deformados da Região de Pien (PR). Provável arco magmático do Proterozóico Superior. In: CONGR. BRÁS GEOQ., 3. São Paulo, 1991. Resumos e Breves Comunicações... São Paulo, SBG. v. 1, p. 249-253.

MANTOVANI, M.S.M.; HAWKSWORTH, C.J.; BASEI, M.A.S. 1987. Nd and $\mathrm{Pb}$ Isotope Studies Bearing on the Crustal Evolution of Southeastern Brazil. Rev. Bras. Geoc., 17(3):263-268.

MANTOVANI, M.S.M.; SHUKOWSKI, W.; BASEI, M.A.S.; VASCONCELLOS, A.C.B.C. 1989. Modelo gravimetria) das principais descontinuidades crustais nos terrenos pré-cambrianos dos Estados do Paraná e de Santa Catarina. Rev. Bras. Geoc., 19(3):367-374.

SIGA, O., Jr. 1986. A Evolução Geotectônica da Porção Nordeste de Minas Gerais, com Base em Interpretações Geocronológicas. São Paulo. 121 p. (Dissertação de Mestrado, IGUSP).

SIGA, O., Jr.; BASEI, M.A.S ; KAWASHITA, K. 1990. Perfil térmico K-Ar através do maciço de Joinville (PR e SC) e do Cinturão Dom Feliciano (SC). Implicações tectônicas. In: CONGR. BRAS. GEOL., 36. Natal, 1990. Anais... Natal, SBG. v. 6, p. 2773-2785.

SELVA, L.C. 1984. Os terrenos de médio a alto grau do pré-cambriano de Santa Catarina. In: CONGR. BRÁS. GEOL., 33. Rio de Janeiro, 1984. Anais.. Rio de Janeiro, SBG. v. 3, p. 3069-3080.

SILVA, L.C. 1987. Geologia do pré-cambriano/eo-paleozóico de Santa Catarina. In: SELVA, L.C. \& BORTOLUZZI, C.A. eds. Texto explicativo para o Mapa Geológico do Estado de Santa Catarina. Florianópolis, CPRM. p. $12-90$.

SOARES, PC. 1988. Tectônica colisional em tomo do Bloco Paraná, Brasil. In: CONGR. LAT. AM. GEOL., 7. Belém, 1988. Anais... Belém, SBG. v. 1, p. 63-79.
MANUSCRITO A723 Recebido em 2 de abril de 1992 Revisão do autor em 12 de maio de 1992 Revisão aceita em 12 de maio de 1992 